\title{
La construcción de identidades en narrativas conversacionales: las implicaciones del medio televisivo
}

\author{
Lil Arrieta y Enrique Martín ${ }^{1}$ \\ Universidad de Cartagena
}

\section{Resumen}

El objetivo propuesto en este artículo es dar a conocer la experiencia de investigación sobre el análisis de las interacciones entre un grupo de niños y niñas inscritas en un género conversacional. Como aspectos a resaltar se encuentran, en primer lugar, las implicaciones que tienen los relatos audiovisuales en la construcción de identidades, lo cual se manifiesta en las elecciones temáticas y referentes compartidos por los participantes. En segundo lugar, se pone de relieve el papel que cumple la narrativa conversacional en la configuración del sentido y la construcción de significados en la cultural.

Palabras clave: construcción de identidades, narrativas conversacionales, discurso, cultura, relatos audiovisuales.

\begin{abstract}
The proposed objective of this article is to disclose research experience in the analysis of the interactions within a group of girls and boys at the level of a conversational genre. In the first place, the implications of audiovisual narratives in the construction of identities are present in the text as highlighted aspects, its importance is manifested in the preference of the participants for the same topics and referents. In the second place, the role of these narratives in the configuration of meaning and the construction of cultural significance is made relevant.
\end{abstract}

Key Words: Identities construction, Conversational narratives, Discourse, Culture, Audiovisual narratives.

\footnotetext{
${ }^{1}$ Profesionales en Lingüística y Literatura de la Universidad de Cartagena. El presente ensayo se fundamenta en el trabajo de campo realizado para la monografía Relatos de identidad en las narrativas conversacionales de un grupo de niños de ocho a diez años estudiantes del colegio Nuestra Señora de Fátima de Cartagena. e-mail: arrieta.lil@gmail.com
} 
"Pertenecer a una cultura viable es estar ligado a un conjunto de historias interconectadas, aunque esta interconexión no suponga necesariamente un consenso".

Jerome Bruner, Actos de significado.

Generalmente es a través de los intercambios verbales como negociamos los significados culturales, aquellos que versan sobre la conducta y la dimensión afectiva e intencional de los seres como partes integrantes de una sociedad. Las narrativas conversacionales se constituyen en una de las prácticas comunicativas más utilizada por los seres humanos en la cotidianidad. Utilizaremos este término en el sentido manejado por el antropólogo Elinor Ochs (2000), para quien las narrativas conversacionales ocupan un lugar central dentro del género discursivo de la conversación cotidiana de experiencias personales por cuanto es utilizado frecuentemente en los actos lingüísticos cotidianos: "La actividad narrativa es [...] un medio discursivo para la exploración y resolución colectiva de problemas; también constituye un instrumento para instanciar identidades sociales y personales" (Ochs, 2000: 297) ${ }^{2}$.

La interconexión de historias y relatos que confieren sentido a nuestro mundo en gran parte se encuentra permeada por los discursos mediáticos que circulan en una creciente cultura de información. Sabemos que la hegemonía de la televisión se constituye en un fenómeno mundial que tiene "hegemónicas" repercusiones en las prácticas socio-discursivas, en la forma como organizamos el tiempo, como concebimos la vida y como comprendemos los discursos. La dimensión lingüística, como expresión del ser, adquiere también nuevas formas de acción.

La creación de relatos y mitos que confieren sentido a nuestra cultura se halla de igual manera inmersa en esta dinámica social. Pero esto sólo se puede observar en los usos del lenguaje, en las formas lingüísticas que expresan los sujetos en situaciones concretas del acontecer diario. Por lo tanto el objetivo del presente trabajo es determinar las implicaciones de las narrativas audiovisuales en la construcción de identidades a partir de la identificación de los temas

${ }^{2}$ Elinor Ochs, profesor de la Universidad de California, trabaja las narrativas conversacionales, especialmente en la cena como evento familiar. Distingue un conjunto de géneros narrativos tales como chismes, redacción de cuentos, cuentos míticos, actuaciones narrativas y las narrativas conversacionales, objeto de estudio de sus investigaciones. 
predominantes en las narrativas conversacionales de un grupo de niños. Este grupo de niños está conformado por Wendy, Samai, Jan Carlos, Enmanuel y Esteven, los cuales se encuentran entre los ocho y diez años de edad. Las muestras discursivas que constituyen el objeto de análisis fueron recopiladas a través de grabaciones de conversaciones informales en el Colegio Nuestra Señora de Fátima de Cartagena durante un período de tres meses.

Durante este trabajo de campo llevamos a cabo un proceso dinámico que nos permitió conocer sus voces, como el compartir de filmes, la lectura de cuentos y dibujos libres. La selección del grupo de cinco niños se realizó de forma aleatoria. Previamente llevamos a cabo una serie de actividades lúdicas que favorecieron el acercamiento y nos ayudaron a ir cerrando el margen de los participantes hasta lograr conformar el grupo con el cual llevamos a cabo nuestro trabajo de investigación.

Para fines de organización metodológica seleccionamos una muestra representativa de las narraciones registradas durante tres meses, pues de esta forma podemos dar a conocer los ejes temáticos reiterativos que se constituyen en referentes compartidos por los participantes en la construcción de sus narraciones.

Durante el proceso de socialización con los niños participamos como co-narradores, es decir, como interlocutores en las conversaciones. Según Ochs,

\begin{abstract}
Algunos estudiosos de la narrativa sostienen que los autores de las narraciones no son solamente aquellos que las presentan sino también los muchos lectores e interlocutores que influyen en la dirección de la narración. Esta autoría resulta bien evidente en las narraciones conversacionales, en las que los interlocutores hacen preguntas y comentarios, y además, contribuyen explícitamente a un relato en desarrollo (2000: 280).
\end{abstract}

Partimos de la idea de que el discurso no es simple reflejo de la realidad, sino que en la interacción verbal se crean y comparten referentes, imágenes discursivas y modelos de las personas que somos y podemos llegar a ser, es decir, se crean campos de posibilidades. En este sentido surgen interrogantes que hacen referencia a las implicaciones que las nuevas narrativas audiovisuales tienen en el discurso que los niños construyen sobre sus experiencias cotidianas: 1 . ¿Cuáles son esas nuevas figuras representativas con las que se identifican?, 2. ¿De qué forma intervienen en su imagen discursiva y en su proyección en el 
tiempo? La identificación de temas y discursos narrativos presentes en las conversaciones implica reflexionar sobre la intencionalidad comunicativa y los contextos sociales en los cuales se producen los enunciados. Y además, establecer las características presentes en las narraciones construidas por los niños, con el fin de dar cuenta de las elecciones temáticas de que éstos se valen para crear significado. Éste último entendido como aquello que se origina en la interacción misma, en el momento de relatar sus experiencias, en el contexto social y cultural en que se inscriben, y no como procesamiento de información o apropiación de categorías gramaticales.

Teniendo en cuenta lo anterior nos interesa ante todo identificar, a partir del grupo de niños seleccionados: 1. ¿Cuáles son los relatos espontáneos, recursivos, propios del acontecer de su vida cotidiana? y 2. ¿Cuál es su contenido temático?, ¿por qué motivo los referentes compartidos por los niños en las conversaciones apuntan, en su gran mayoría, a los relatos ofrecidos por la televisión?.

En el análisis de los temas propuestos por los niños y niñas participantes encontramos que la telenovela mexicana Rebelde (producida por Televisa y transmitida por primera vez el 4 de octubre del 2004 en la programación colombiana RCN Televisión) y las transmisiones de fútbol ocupan un espacio importante en sus referentes compartidos. Hay que anotar que en esta reflexión queremos resaltar no sólo la elección temática sino también, y no menos importante, el papel del discurso narrativo en el que los niños se reconocen, comparten experiencias y acceden al significado de la cultura (Cf. Bruner, 2000).

El trabajo de Anita Pomerantz y B. J. Fehr, “Análisis de la conversación: enfoque del estudio de la acción social como prácticas de producción desentido" (2000) resultapertinentecomo herramienta metodológica para el análisis. De manera que tendremos en cuenta las siguientes dimensiones para la reflexión sobre las prácticas discursivas:

- Selección de una secuencia narrativa.

- Caracterización de las acciones dentro de la secuencia.

- Identificación del tema central o principal de la conversación.

- Reflexión sobre las identidades, roles y/o relaciones de los participantes. 


\section{Atravesando el espejo televisivo La infancia: entre el drama y la pelota}

\section{La telenovela Rebelde en la representación de las experiencias}

El género discursivo de la conversación cotidiana crea un contrato social de habla entre los participantes en el que cada uno interviene, toma la palabra e "invita" a hablar sobre un tema determinado. Los que participan en este evento discursivo tienen la posibilidad de acoger o rechazar los temas de tal manera que pueda adquirir verdadero interés por parte de los interlocutores. Así mismo se da lugar a las interrupciones y a los silencios. Estas acciones en la conversación se dan gracias a que los hablantes construyen sus ideas acerca de la situación comunicativa en la que se encuentran, acerca de los referentes compartidos con su interlocutor, y de acuerdo a esto, escogen hablar sobre algo que puede generar interés o respuesta. También seleccionan la forma que consideran pertinente o adecuada para expresar sus enunciados. Al respecto, veamos el siguiente caso tomado del grupo niños con quienes se llevó a cabo el trabajo de campo:

[1] Wendy: Acá en el colegio todo el mundo se cree Mía. Con una estrellita aquí y el pelo [2] por acá. (juiciointroduce un tema)

[3] Samai: Ah sí. (aprobación)

[4] L: Así como ella, tiene una estrellita.

[5] Samai: Ella es...ella es Alma (refiriéndose a Wendy) (introduce el tema en sus

[6] experiencias propias).

[7] Es que uno a veces jugamos. (Da información a L, conarrador).

[8] L: A qué juegan? (pregunta)

[9] Samai: a rebelde. Jennifer María es Roberta, yo soy Mía. (respuesta y comentario).

[10] L: por qué eres Mía? (pregunta)

[11] Samai: porque a mí me gusta cómo se viste ella, como actúa. (juicio)

[12] L: Y cómo dice? (pregunta)

[13] Samai: ique "Ay daddy", verdad? (pregunta a wendy)

[14] Wendy: ah sí. Cuando le dice a Roberta "es que Roberto" (aprobación)

[15] Samai: "Roberto ven acá hazme el favor"

[16] Wendy: Cuando tiene rabia: "Roberto ven acá". No le dice Roberta sino Roberto. (aclaración). 
El discurso de la narración se caracteriza precisamente por su capacidad de abarcar una pluralidad de estilos y géneros, como ocurre no sólo en las formas narrativas como la novela, sino también en las conversaciones cotidianas, donde las personas pueden recurrir a intertextos de letras de canciones, a relatos imaginativos contados por una persona que se toma la palabra durante la conversación, ya sea por iniciativa propia o porque así lo han pedido los participantes o conarradores. Es pertinente aclarar que tomamos la palabra intertexto en el análisis de las narrativas conversacionales para dar cuenta de un mecanismo utilizado en el discurso de los niños que consiste en la evocación de otros discursos de la cultura, como las letras de canciones de Rebelde. En ocasiones sus narraciones nos remiten a la esfera de los intercambios verbales con personas cercanas, como la madre. En el caso expuesto, Wendy y Samai representan sus gustos y afinidades con los personajes, mujeres protagonistas de la telenovela Rebelde, a través de las referencias textuales del discurso elaborado por el guión de dicho programa, estrategia que responde de manera concreta y eficaz la pregunta de L: "Y cómo dice" (Mía) [12].

Esta elección de los términos de referencia en el discurso demuestra, por un lado, el conocimiento pragmático de los hablantes en cuanto hacen uso de los recursos utilizados para lograr su intención comunicativa. Es una forma de recrear el discurso. Por otro lado, revela sus representaciones de mundo, el sentido del querer ser, sus deseos, las figuras y valores con los cuales se identifican. En otras palabras, estas expresiones son parte de la construcción de sus subjetividades en el discurso.

En las narrativas conversacionales es de esperar, además, el tipo de respuestas afectivas que nos llevan a identificar gustos, preferencias y personalidades, como cuando Samai expresa: "porque a mí me gusta cómo se viste ella, cómo actúa" [11]. Si el tipo de discurso que genera el medio televisivo va dirigido a la "hipersensibilidad sensorial", a las emociones y estímulos visuales y auditivos, es de esperar que tenga una resonancia en los discursos que los niños ofrecen en sus espacios de socialización: "Si la televisión [...] privilegia la percepción sobre la abstracción, lo sensitivo sobre lo conceptual, es natural que tienda a provocar respuestas de carácter emotivo más que de carácter racional. Lo que significa que las respuestas que solicita la televisión van más en la línea 'me gusta-no me gusta' que en la línea 'estoy de acuerdo-no estoy de acuerdo'” (Ferrés, 1994: 33).

Los modos de leer, leer los libros y la propia vida, y los modos de contar nuestras experiencias, cambian en relación con esos nuevos patrones culturales e imaginarios compartidos por los grupos 
sociales. En los relatos de vida del grupo de niños con quienes trabajamos observamos que su lectura del mundo, la cual antecede a la lectura de signos gráficos, se encuentra protagonizada por esas nuevas figuras representativas de los medios y que se convierten, en determinado momento, en paradigmas del ser y el actuar, pero no dejan de ser cambiantes en la medida en que se propongan y aparezcan en pantalla nuevos modelos con igual o distintos valores. Lo cierto es que son estas cambiantes imágenes identitarias las que desplazan el lugar de las anécdotas propias de la familia o el de la relación con su entorno inmediato, privilegiando los relatos propuestos por la televisión. Nos encontramos frente a lo que Jesús Martín-Barbero señala como "el desencantamiento de sus mundos autocentrados y el reencantamiento que propicia el espectáculo de los medios" (Barbero y Rey, 1999: 33).

Sin embargo, con esto no estamos afirmando la completa desaparición u olvido de sus historias "autocentradas" -aquellas que conciernen a su entorno inmediato: sus relaciones familiares, la escuela y sus relaciones con los compañeros, los juegos, entre otras.- Lo que sí podemos observar es cómo las figuras representativas "impuestas" por la televisión y sus estilos de vida, de lenguaje y comportamiento, aportan de una manera recurrente a las temáticas abordadas en sus narrativas conversacionales. Por ejemplo, Wendy y Samai (las dos niñas informantes de nuestra investigación) hacen referencia a su vida familiar, a los roles que ellas cumplen en el hogar, y no pueden dejar de hablar del ritual diario frente a la televisión y los disgustos que les producen cuando es interrumpida la cita con su programa preferido (Rebelde) por algún miembro de la familia. Igualmente, al hablar de sus gustos y actividades favoritas hacen referencia a aquellos personajes con los que se identifican y quieren llegar a ser:

[1] Samai: a mí a veces me toca lavá los platos y barrer... la sala y barrer...afuera y

[2] echale agua a las matas. Pero yo no le pongo cara a mi mamá. Yo le digo: "bueno [3] mami ahorita, ahorita, porque me estoy viendo Rebelde y bueno ahorita ahorita que

[4] den propaganda".

[5] Wendy: cuando me estoy viendo Rebelde no me quiero hacer ni un mandado

[6] porque "mami pero rápido, que no sea... rá... que no sea tanta cosa que voy a

[7] comprar, entonces voy allá abajo y como allá abajo está el televisor y en mi 
[8] cuarto... me tengo que ir corriendo en la escalera pa que me pueda ver Rebelde

[9] rápido porque si no...

[10] Samai: mi mamá me dice siempre que estoy viendo Rebelde que cuando estén

[11] dando propaganda.

[12] Wendy: yo como ya estoy bañaíta.

[13] Samai: a mí también me gusta bañarme temprano.

[14] Wendy: mi mamá no me regaña cuando me estoy viendo Rebelde pero cuando

[15] estoy castigada que no hago caso y que termine... ahí sí no me lo deja ver... pero

[16] ella siempre está... me lo deja ver a mí.

En el fragmento anterior, que ilustra nuevamente un espacio de diálogo entre Wendy y Samai, observamos que hay un tema inicial: las labores del hogar. Podemos caracterizarlo así en razón de la estructura del primer enunciado en [1] y [2] en la que Samai relata sobre aquello que debe o tiene la obligación de hacer en su casa, tal como es estipulado por su mamá: "A mí a veces me toca lavá los platos y barrer..." [1].

Este enunciado, al igual que los otros que componen esta secuencia, se encuentra expresado en tiempo presente, pues es utilizado aquí para hablar sobre lo que representa una costumbre, una rutina en la vida de Wendy y Samai:

Samai: -Me toca lava los platos y barrer...

-Echarle agua a las matas

-Pero yo no le pongo cara a mi mamá

-Yo le digo: "bueno mami ahorita..."

-Me estoy viendo Rebelde

Wendy: -Cuando me estoy viendo Rebelde

-No me quiero hacer ni un mandado

Samai: -Mi mamá me dice siempre que estoy viendo Rebelde

Wendy: -Mi mamá no me regaña cuando estoy viendo Rebelde

-Pero cuando estoy castigada

-Pero ella siempre está... me lo deja ver a mí.

Ya hemos mencionado que el tema con el que se inicia la conversación hace referencia a las labores en el hogar, lo cual queda explícito en la primera intervención de Samai. Pero vemos que inmediatamente, en 
el mismo enunciado, el foco temático se centra en las interrupciones de la rutina frente al programa Rebelde a causa de las labores o "mandados" que deben hacer para su mamá. En el momento en que Samai dice: "Bueno mami ahorita, ahorita porque me estoy viendo Rebelde y bueno ahorita, ahorita que den propaganda" [2-4] no sólo está narrando algo sobre sus acciones cotidianas, sino que, además, está justificando su modo de proceder ante esta situación frente a su mamá y de esta manera revela su punto de vista de la forma como se debe sobrellevar dicha situación. Para ello resulta pertinente el intertexto que toma de aquello que su mamá, en ese contexto, le responde: "Bueno ahorita ahorita que den propaganda" [3-4].

En este sentido, la narración cumple la función de dar a conocer sus experiencias cotidianas y de atribuirles un sentido en el lenguaje en el acto mismo de relatarlas en el evento social de la conversación y, aun más, lograr un acuerdo o aceptación de aquello que ocurre en sus vidas. Es aceptado en tanto es expresado como patrón de comportamiento, como un guión narrativo que reitera las normas sociales en las cuales nos hallamos inmersos, en este caso, en el entorno familiar. Sirve además, según el caso que aquí se trata, para reconocerse a ellos mismos e interactuar con los demás. De allí que a través de las narraciones logran un saber no sólo discursivo sino también pragmático, puesto que obtienen un conocimiento sobre aquello que deben o no deben decir, ante quién y qué resulta pertinente para llegar a un acuerdo.

Algunos enunciados o temas propuestos en la interacción pueden convertirse en convocadores del discurso y, generalmente, son aquellos temas que involucran al interlocutor en la medida en que se constituyen en referentes compartidos. En la intervención de Wendy observamos que acepta y comparte el tema propuesto por Samai: su rutina diaria frente a su programa favorito, Rebelde. Éste adquiere relevancia en cuanto tiene que ver con los deseos compartidos y, además, las obligaciones (obligación/deseo): "Cuando me estoy viendo Rebelde no me quiero hacer ni un mandado, porque 'mami pero rápido, que no sea... rá...'” [5-6].

Wendy expresa de modo más directo aquello que Samai nos hablaba sobre las obligaciones y el deseo. Así mismo, utiliza el recurso de traer a la narración presente los discursos que ella utiliza con su mamá para describir el acto de justificar o pedir algo, en este caso, que no interrumpa cuando se está viendo Rebelde. Es así como la vida misma, "la vida en acción", es fuente de imitación en los relatos, imprimiéndoles un sentido de lo real, el movimiento, la acción, las voces de otros personajes, en este caso de su mamá, ya sea que 
adquiera voz propia, como ocurre en la narración de Samai: "bueno ahorita ahorita que den propaganda", o adquiera protagonismo como co-narradora del relato: "mami pero rápido, que no sea... rá..." [6].

En los dos casos, estas elecciones resultan de gran valor ya que introducen a las interlocutoras en el propio mundo de su cotidianidad y brindan una explicación de lo que ellas consideran como justo o injusto en su hogar con relación a las labores familiares y su ritual frente al televisor. Por eso, casi al final de la secuencia, Samai ratifica la regla de acuerdo con su mamá: "Mi mamá me dice siempre que estoy viendo Rebelde que cuando estén dando propaganda". Wendy también nos reitera la norma en su hogar: "Pero cuando estoy castigada que no hago caso... y que termine... ahí sí no me lo deja ver" [14-15].

Lo que los informantes han hecho no es sino recordar, nombrar, y al hacer esto están legitimando o haciendo conciencia de aquello que han aprendido como un acuerdo, una norma de vida, que en este caso aceptan sin dificultad o conflicto alguno y se conecta directamente con aquello que deben y quieren hacer, las obligaciones y los deseos. Pero al tiempo que comparten estos estados intencionales los ubican en un contexto social específico: el acto de ver televisión, un estatus, un lugar sagrado en la cotidianidad y en sus formas de relacionarse en el ámbito doméstico. Según McLuhan, "el circuito eléctrico da una dimensión mítica a nuestros actos individuales y grupales ordinarios. Nuestra tecnología nos obliga a vivir míticamente, pero seguimos pensando en forma fragmentaria y en planos aislados, independientes entre sí" (McLuhan y Fiore, 1998: s. p.). Esto quiere decir que la televisión impone nuevas formas de estar, hábitos de vida que irrumpen en la vida privada: le otorgamos un espacio $\mathrm{y}$ un tiempo sagrado a determinados programas, adquirimos compromisos con ellos y se convierten en fuentes de encuentros, de diálogo, de interacción con los otros.

Hemos visto cómo se establece una interacción comunicativa donde las intenciones, los deseos y compromisos, así como la relación con el entorno inmediato, se ponen de manifiesto a través de las narraciones: el análisis de la estructura temática da cuenta de ello. Hasta aquí podemos afirmar que la elección y el tratamiento de un tema compartido generan el intercambio de juicios valorativos, de los relatos que recrean los juegos y demás referentes compartidos por los niños. De allí que analizar el contenido temático de las narraciones conversacionales implique un conocimiento general de sus actitudes, su forma de ser que, lógicamente, durante el trabajo de 
campo realizado aumentó en la medida en que participamos como co-narradores en el diálogo instaurado con los niños.

Retomando el carácter heterogéneo y plural del género conversacional, resulta importante destacar el papel que juega la composición o interpretación de las canciones como dimensión de la función expresiva. Esto pone de manifiesto la recursividad de las narraciones y las distintas formas discursivas para dar a conocer las intenciones en la situación comunicativa constituyéndose en un acto de habla: la declaración de amor.

En el marco de este género cabe esperar que los deseos y valores se expresen no sólo en el diálogo cara a cara, sino que además tomen forma en la re-invención y re-creación de las letras de canciones, adaptándolas a las circunstancias presentes en el momento de la interacción. Este es el caso de José Esteven, quien en diversas ocasiones recurre a la inventiva y a su repertorio musical para hacer saber su sentimiento a una compañera:

[1] Esteven: una champetica ahí (petición).

[2] J. Carlos: Edda pilas... "Rebelde" de Samai, vamos a ponerle el título de Samai,

[3] el disco de Samai y José Esteven. Habla ombe (introduce la interpretación)

[4] Esteven: yo tengo qué poco [de canciones].

[5] “Te beso, te siento, me dices que (...) Te beso despierto me dices qué beso con

[6] una lágrima derramas me abrazas, te beso, me pides un beso y tú te quedas sin

[7] respirar sólo dame ese beso, ese beso, sólo dime... sólo dime... soy... sólo dime

[8] te beso, sólo bésame en silencio cinco minutos, acaríciame un momento, ven...

[9] J. Carlos: Samai ven

[10] Esteven: ven junto a mí, te daré el último beso el más riquito, guardaré

[11] mis sentimientos, besaré lejos de ti”... ya ahí.

La intención de interpretar una canción para su compañera es realizada a través de una petición inicial: "una champetica ahí” [1], la cual es respaldada por J. Carlos. Es éste quien introduce de antemano el tema de la canción: "Rebelde de Samai", caracterizándolo como "el disco de Samai y José Esteven". Esta acción nos permite a los interlocutores identificar qué tipo de canción es: una canción que interpreta el grupo $R B D$, de género romántico, conocida por todos 
ellos. J. Carlos establece una analogía entre lo que es el mundo de la pantalla y sus compañeros, Esteven y Samai, como una manera de convertirlos en protagonistas de la telenovela. Ellos protagonizan su propio mundo, el de la interacción comunicativa tal como lo demuestra José Esteven.

Esto es un ejemplo de la capacidad que tienen las narraciones no sólo en el dominio de sus expresiones lingüísticas, sino también como acciones dirigidas a un fin determinado, y la forma cómo los niños las llevan a cabo habla sobre lo que son, sus identidades y lo que esperan de las otras personas: "Desde nuestra perspectiva, decimos que si bien aceptamos que determinados interpretantes conducen a determinadas acciones, no es menos efectivo, sostenemos, que las acciones también generan las interpretaciones capaces de conferirles sentido [...] vivimos en mundos interpretativos" (Echeverría, 2002: 92).

Hay que anotar que la canción adaptada por José Esteven tiene una temática recurrente que gira en torno a las sensaciones. Sus relatos dan cuenta reiteradamente de los juegos que impliquen el acercamiento con sus compañeras, de los besos, de sus intimidades. En el intertexto de su canción observamos que la palabra que más se repite es "beso". Esta retórica del amor que caracteriza las canciones de Esteven hace referencia a un mundo donde prima lo sensorial y el placer del cuerpo. Las imágenes recurrentes versan sobre el amor despojado de toda sutileza e inocencia. Observamos que este locutor crea su propio sentido, es decir, aquello que él quiere hacer-saber: su declaración de amor. Por ello recurre a la semántica de "los besos" y los sentimientos más que al contenido mismo, el cual alude al carácter de ruptura que se plantea entre padres e hijos. Su canción no tiene que ver nada con la manera como los padres perciben el mundo, sino con su intención en la situación comunicativa.

La siguiente es una muestra de la letra original de la canción "Sólo quédate en silencio" de RBD y de la interpretación hecha por Esteven, adaptada al ritmo popular-local en cuya letra prima lo sensualsexual:

Te encuentro despierto me dices lo siento con una lágrima derramas / me abrazas me hielo me pides un beso y yo me quedo sin respirar/ Sólo espera un momento sólo dime no es cierto/ Sólo quédate en silencio cinco minutos,/ acaríciame un momento ven junto a mí /te daré el último beso el más profundo/ guardaré mis sentimientos y me iré lejos de ti. 
Canción adaptada por Esteven:

Te beso, te siento, me dices que [...] Te beso despierto me dices qué beso con una lágrima derramas/ me abrazas, te beso, me pides un beso y tú te quedas sin respirar/ sólo dame ese beso, ese beso, sólo dime... sólo dime... soy... sólo dime te beso,/ sólo bésame en silencio cinco minutos,/ acaríciame un momento, ven [...] ven junto a mí,/ te daré el último beso el más riquito,/ guardaré mis sentimientos, besaré lejos de ti" [...] ya ahí.

Tomemos el siguiente fragmento en donde Esteven selecciona como intertexto otra canción de la misma telenovela Rebelde $\mathrm{y}$ comparémosla con la letra original:

Canción adaptada por Esteven:

Mientras mi mente viaja a donde tú estás / [...] Samai me besa otra vez/ que tú me diste ese besito con paz, dame el besito de ayer/ Aunque me escuches ya te beso aquí cierro los ojos y ya estoy besando aquí/ y soy rebelde cuando te tengo que besar y soy rebelde cuando... cuando te beso como [...] y soy rebelde [...] (risas).

Canción "Rebelde" de RBD:

Mientras mi mente viaja a donde tú estás/ mi padre grita otra vez/ que me malgasto mi futuro y su paz con mi manera de ser,/ aunque lo escucho ya estoy lejos de aquí cierro los ojos y ya estoy pensando en ti/ y soy rebelde cuando no sigo a los demás y soy rebelde.

\section{El fútbol y los juicios de valor como generadores de sentido}

En las conversaciones generalmente realizamos actos declarativos, emitimos juicios de valor sobre temas o situaciones de la vida en los que nos sentimos "competentes" o con la autoridad necesaria para polemizar sobre algunos aspectos. El fútbol es un referente compartido al que los niños recurren con mucha frecuencia, pues tienen la oportunidad de emitir juicios con respecto a sus equipos, a sus jugadores favoritos, dando paso a las discrepancias, a la defensa propia frente a los otros. De este modo forma el fútbol se convierte en una forma de identificarse en el grupo, tanto más cuando cada uno representa un equipo diferente. Es una etiqueta de presentación 
ante los otros. Por esta razón los juicios valorativos se constituyen en una fuente importante de la identidad de las personas:

Los juicios pertenecen a la clase de actos lingüísticos básicos que llamamos declaraciones. Como sabemos, las declaraciones son muy diferentes de las afirmaciones. Ellas generan mundos nuevos [...] con ellas creamos una realidad nueva, una realidad que sólo existe en el lenguaje. Si no tuviéramos lenguaje, la realidad creada por los juicios no existiría. Los juicios son otro ejemplo importante de la capacidad generativa del lenguaje. No describen algo que existiera ya antes de ser formulados [...] la realidad que generan reside totalmente en la interpretación que proveen. Ellos son enteramente lingüísticos (Echeverría, 2002: 110-111).

Esta cita de Rafael Echeverría nos recuerda la capacidad que tienen los juicios de valor para crear compromisos con aquello que decimos, porque la realidad y nuestra condición como seres humanos no es algo ya dado sino que creamos en el lenguaje, en nuestras expresiones y acciones. Y por supuesto, todo ello comprende nuestras formas de ser, nuestra identidad.

El siguiente fragmento es una muestra representativa de las conversaciones impulsadas por los narradores, es decir, aquellas en las que el discurso de los niños toma su forma de tal modo que la intervención de los co-narradores no se hace necesaria, lo cual no quiere decir que no estén presentes en el contexto de la conversación; incluso, son implicados en ellas por los narradores para cumplir una función fáctica, es decir, para mantener el contacto y reafirmar la presencia de éstos en el curso de la conversación:

[1] Enmanuel: a la abuela quien inventó tu papá Nacional pregúntale a Enrique.

[2] Esteven: los maricas inventaron el América (risas)

[3] J. Carlos: Ay los maricas inventaron el América (remedando)

[4] Enmanuel: los policías inventaron el Nacional. Los policías inventaron al

[5] Nacional, ¿por qué?... los policías inventaron al Nacional pregúntale a Enrique

[6] ed vale mía... que eso... eso nada más es un equipo y eso lo inventaron ese

[7] equipo.

[8] J. Carlos: Ay él (Enrique) puede decir todo porque él le da al Nacional ay yo 
[9] le doy al Nacho, entonces yo digo el Nacho lo inventaron porque yo le doy al

[10] Nacional.

[11] Enmanuel: lo inventó la policía mi hermano.

[12] Esteven: Quién dijo ombe...

[13] Enmanuel: la misma policía tiene verde y blanco.

[14] Esteven: y el verde lo inventó la policía?

[15] Enmanuel: El América, el América lo inventó (irónico).

[16] Esteven: yo le doy al (-) ombe. (risas). Y que la policía inventó al Nacional

[17] está loco ombe, el Nacional se inventó sólo ombe.

[18] J. Carlos: embuste, que el Nacional no se inventó solo, el que inventó el

[19] Nacional fue el técnico (Esteven y Enmanuel se burlan).

[20] Esteven: estás loco ombe...

[21] J. Carlos: Él le da al Nacional... y que al Nacional... al América... y tiene el

[22] suéter más pleno y es el más maluco, debe tener el suéter más pleno ¿ah? Porque él

[23] le da al América.

[24] Enmanuel: yo veo que, yo veo que este pelao es tronco e pastelero porque él

[25] le daba al Nacional (se refiere a Esteven).

[26] Esteven: ¿yo? ¿Yo?

[27] J. Carlos: Ah no, yo (irónico).

[28] J. Carlos: eso es verdad porque él no... le iba al Nacional. (se refiere a Esteven).

[29] Enmanuel: Tú mismo lo confesaste, tú mismo lo confesaste. (a Esteven).

[30] Esteven: yo le voy al América y qué.

[31] Enmanuel: primero y que el América lo creó los ya tu sabes y ahora y que... y que...

En la primera línea del fragmento discursivo podemos identificar el tema que guía la conversación a través de la expresión nominal: "tu papá Nacional”. Es la que orienta la acción hacia un discurso en torno a los equipos de los que los participantes son "hinchas": el América y el Nacional. Por otra parte, nos indica que Enmanuel es hincha de éste último por el tipo de expresión que utiliza: "tu papá Nacional" [1], connotación de autoridad, de imposición, de respeto y grandeza. Al emitir su juicio busca una fuente de respaldo que le confiera seguridad y fundamento a lo que ha dicho. Por esto hace referencia a Enrique, co-narrador, sobre el conocimiento previo de que éste es 
hincha del mismo equipo: "pregúntale a Enrique" [1]. Con respecto al participante Esteven, sus intervenciones nos revelan más bien una intención de crear polémica y contrariar antes que dejar en claro cuál es su equipo. "Los maricas inventaron el América" [2], comentario que va dirigido en especial a J. Carlos, hincha de este equipo, quien le responde con un tono irónico.

Como ya hemos anotado, es claro que el tema de las narraciones está centrado en los equipos de fútbol: Nacional y América. Un análisis desde los referentes en el discurso nos ayuda a comprender su estructura temática, según lo que denominan Russell S. Tomlin y Linda Forrest (2000) como gestión referencial en el discurso. De acuerdo a esto existe una información dada en el discurso que es la que se repite en mayor grado y por tanto se constituye en referente compartido por los hablantes, mientras que la información nueva es aquella que no tiene acogida en el discurso o no aparece repetida en el mismo:

Un problema importante en el manejo de la referencia ha sido comprender cómo hablante y oyente pueden mantener un registro de los referentes durante la producción y comprensión del discurso. Mantener un registro de los referentes involucra tres problemas relacionados: 1) introducir referentes en el discurso, 2) mantener la referencia una vez se introdujo un referente y 3) reintroducir referentes después de un intervalo prolongado (Tomlin y Forrest, 2000: 130).

En los enunciados de la muestra se repite una información por parte de los tres participantes cuyo núcleo podríamos identificarlo como: "Inventar el Nacional" y toda una gama de variaciones: el Nacional se inventó solo, el que inventó el Nacional fue el técnico y la policía inventó el Nacional. Esto nos lleva a afirmar que el fútbol se constituye en un tema frecuente de conversación y en un referente cultural compartido por todos. Hay que anotar que en las niñas el tema del fútbol se da de una forma diferente, pues se desarrolla en la esfera privada, es decir, hablan sobre las experiencias y los partidos de fútbol dentro de la escuela, en donde ellas participan colectivamente, como grupo, frente a otras niñas. Es allí donde se reconocen e identifican como partes integrantes de una comunidad determinada y se asignan valores expresados a través de juicios como "yo veo que este pelao es tronco e pastelero porque él le daba al Nacional" [24-25]. Enmanuel hace referencia a Esteven pero, como hemos observado, éste adopta una actitud poco clara con respecto a 
su identidad respecto a su afiliación con un grupo determinado, más bien busca llevar la contraria al resto de los participantes.

El acto de narrar nuestras experiencias cotidianas genera cierto tipo de compromiso con aquello que decimos. Aunque emitamos enunciados en un tiempo verbal pretérito, adquirimos conciencia del presente, de nuestras motivaciones en el ahora y de nuestras posibles acciones futuras. De allí que las narraciones sean propicias para crear ese espacio de compromiso con lo que decimos y nuestros actos concretos, en donde además comprometemos el pasado, el presente y el futuro, tal como lo hace el juicio que emite Enmanuel con respecto a los enunciados de Esteven: "Tú mismo lo confesaste, tú mismo lo confesaste" [29]. De esta manera juzga o valora lo que Esteven ha dicho y el hecho de no comprometerse con sus actos lingüísticos: Esteven, en el pasado, ha dicho que era hincha del Nacional, pero actúa como si no lo fuera, de ahí que Emmanuel lo califique como "pastelero" [24] y juzgue su conducta, una conducta que bien se puede denominar "acción discursiva": "Primero y que el América los creó los ya tú sabes...” [31].

En este mismo orden de temas la creación de relatos en torno al fútbol toma otra forma de concreción, cual es la de la invención de historias. Con el nombre de "génesis del fútbol" hemos denominado un relato que surge gracias a la petición hecha por el co-narrador con el fin de socializar los dibujos libres realizados en una actividad grupal. Al pedírsele a los niños que nos hablaran sobre lo que habían dibujado, observamos que la respuesta-acción de Enmanuel fue narrar una historia, y a través de una forma de organización narrativa ofrece explicaciones y re-crea toda una historia creativa:

[1] Enmanuel: "Érase una vez un señor / que vivía en esta casa ya que este señor le gustaba

[2] jugar. Y un día se inventó una clase de juego y el hombre le puso fútbol. / Y él llamó a

[3] uno de sus abogados, uno de los dueños de esta fábrica que está acá y él le dijo todo

[4] entonces... este... llegó y llegó a la casa del alcalde y habló con él y ahí

[5] estaba hablando sobre un juego llamado fútbol que se necesitan unas pelotas unas [6] pelotas y un juego que se juega a rajar y todo eso, entonces el alcalde mandó a la

[7] fábrica, esta fábrica acá están fabricando objetos para hacer la... un objeto que también [8] le llamaron cancha, entonces ellos aquí estaban haciendo, estaban haciendo 
la cancha y [9] de aquí llegamos acá otra fábrica. Esta fábrica les estaba dando los instrumentos que [10] necesitaba y acá estaban haciendo... y esta es una fábrica de los objetos que

[11] necesitaban estaban inventando la fórmula y aquí hicieron ya una cancha / Y así

[12] inventaron el juego este / Y así jugaron y jugaron y se inventaron jugadas".

Tomemos la definición de relato planteada por Erving Goffman (citado por Ochs, 2000):

En el sentido más acabado del término, el relato es una enunciación derivada de la perspectiva personal de un participante real o potencial que está situado de modo que algún desarrollo dramático temporal del suceso informado avanza desde ese punto de partida. Por eso, una repetición será, a propósito, algo en que los oyentes pueden insertarse empáticamente y volver a experimentar de manera vicaria lo que acaeció. En suma, un relato cuenta una experiencia personal y no es tan sólo un informe sobre un suceso (283).

De la definición de relato que nos ofrece Erving Goffman nos interesa ante todo resaltar que la construcción del relato comprende la perspectiva personal del participante, así como su intencionalidad, punto de vista y experiencias personales. Es así como podemos hablar de una representación del mundo presente en el texto. Al contar una historia estamos expresando algo de lo que somos, de nuestras inquietudes y proyecciones en el tiempo.

Analizaremos la estructura del relato presentado por Enmanuel teniendo como guía el modelo que propone William Lavob, referenciado en Elinor Ochs (2000: 286). Para identificar el asunto de la narración distinguiremos las partes que componen el texto y que confieren un sentido coherente, una secuencia lógico-narrativa:

1. Prefacio narrativo: "Érase una vez un señor...".

El inicio de la narración nos introduce en el marco de una historia perteneciente al mundo fantástico, un cuento producto de la imaginación del hablante, y nos promete, además, el desencadenamiento de un acontecimiento relacionado con el sujeto que hace explícito: "un señor". Lo que presenta a continuación es una orientación del rumbo que toma su relato y se constituye, además, en 
un resumen de la historia, aquello a partir de lo cual se desarrollaran las acciones.

2. Resumen-orientación: “...un señor que vivía en esta casa ya que este señor le gustaba jugar. Y un día se inventó una clase de juego y el hombre le puso Fútbol" [1-2].

Esta secuencia narrativa cumple la función de caracterizar al personaje enunciado en el inicio del relato: de esta forma conocemos que al señor de la historia le gustaba jugar. Pero la acción principal es la que resume el tema central del relato: "Y un día se inventó una clase de juego y el hombre le puso fútbol”.

Primero que todo, identifiquemos la relación anafórica que se establece en el texto: "El hombre", expresión nominal referida a "El señor", presente en la primera línea de la narración. En este fragmento ya el narrador nos ha brindado una información valiosa con respecto al contenido o asunto de su relato. Algo que hemos denominado "La génesis del fútbol". Es particularmente interesante la forma como este enunciado que cumple la función de resumen nos remite al mito de la creación del mundo, estableciendo así una analogía: Dios creó algo y lo bautizó, le puso nombre. En el relato un señor inventó una clase de juego y le puso fútbol.

El fútbol, en este contexto narrativo, se erige como algo sagrado en la vida. Se constituye en un referente ampliamente compartido por los niños en sus narraciones y experiencias cotidianas. Así, cumple un papel importante en la construcción de identidades, crea valores y sentido de pertenencia a una comunidad que comparte sus mismos compromisos para con este juego.

3. Complicación de la acción: "Y él llamó a uno de sus abogados, uno de los dueños de esta fábrica que está acá... y aquí hicieron ya una cancha..." [2-11].

Reconocemos esta secuencia narrativa como aquella donde se lleva a cabo el proceso de creación del fútbol, en donde Enmanuel introduce una serie de personajes: abogados, alcalde, dueños de fábricas; objetos: pelotas, cancha, fórmula. Él le está dando nombre a cada uno de los elementos que conforman el juego. Lo cual finaliza con la expresión: "Y aquí hicieron ya una cancha" [11]. En la siguiente parte del relato sintetiza todo este proceso a través de una expresión de resolución, de cierre.

4. Resultado: “...y así inventaron el juego este” [12]. 
5. Coda: "Y así jugaron y jugaron y se inventaron jugadas" [12]. Enmanuel nos revela a través de su relato la imagen de un juego en el que todo está organizado como una empresa: fábricas, abogados, alcalde. Todo ello nos proporciona la idea de una industria, de toda una maquinaria de producción. El fútbol ha sido erigido por la televisión como la gran empresa cuyos protagonistas, figurasmodelos, son los jugadores, y no es de extrañar que cada niño y joven tenga su equipo favorito, pero además su jugador "estrella". Una de las funciones que cumple el medio televisivo es crear imágenes y referentes de acontecimientos o sucesos de los escenarios deportivo, artístico y de la vida privada (ejemplo de ello son los reality shows donde se dramatizan y se convierten en material relevante las emociones y reacciones de las personas ante los juegos, concursos y competencias).

En este sentido, podríamos decir, en palabras de Joan Ferrés (1994), que la televisión cumple el papel de la madre y el tótem, estableciendo una relación metafórica para definir la nueva forma de organización social, "modernas tribus":

La televisión es vestigio de lo sagrado, del que las modernas tribus esperan toda clase de beneficios. Es la nueva religión. Lo es porque, recuperando el sentido etimológico del término, provoca un religare, es decir, una nueva forma de atar al ciudadano con el mundo, una nueva manera de relacionarlo con la realidad. En torno a ella se celebran los modernos rituales individuales, familiares y sociales. (Ferrés, 1994: 13)

\section{A manera de conclusión}

El análisis del conjunto seleccionado de narrativas conversacionales nos ha conducido a una serie de planteamientos concernientes a la conformación de identidades en el discurso. En primer lugar, es importante resaltar que estas identidades en construcción parecen estar más sujetas a los discursos audiovisuales de los medios que al espacio territorial donde los niños y niñas interactúan trayendo como consecuencia una "disminución de la importancia de lo territorial y de los referentes tradicionales de identidad" (Barbero y Rey, 1999: 19). Muestra de ello es la notoria presencia de intertextos de la telenovela Rebelde, ya sea de los guiones de las protagonistas o de la música que interpreta este grupo musical.

Hablar de las actividades cotidianas en el hogar implica el relato de su ritual diario frente a la televisión. Esto es significativo en la medida en que sus relatos autocentrados se alimentan de sus experiencias 
televisivas y las identificaciones con los personajes creados por sus programas favoritos. Siguiendo la misma línea temática, Esteven reinventa la letra de dos canciones de Rebelde compartiendo un mismo código de comunicación con sus amigos con el fin de realizar su declaración de amor. La lectura de las narrativas conversacionales anteriormente descritas genera interrogantes sobre la función moldeadora que cumplen los medios en la construcción de nuestros relatos. Es decir, abre un campo de reflexión acerca de las repercusiones que éstos pueden tener en las elecciones temáticas y referentes compartidos entre ellos en el género del diálogo cotidiano. Por otra parte, resaltamos las características que los niños imprimen a su discurso narrativo, apelando al carácter dramático, a la recreación de otras voces, ya sea de personajes de la familia o del mundo de la pantalla, a las interpretaciones musicales, el ritmo, el dinamismo, las imitaciones, entre otras.

Los juicios de valor, en su mayoría, versan sobre tópicos comunes entre los niños. El fútbol es uno de ellos. No sólo genera compromisos con lo que se afirma con base a sus equipos y jugadores favoritos sino que crea identidades y proyecciones en el futuro. Cabe anotar que la televisión ha construido la imagen del fútbol como todo un escenario de espectáculo y de protagonismo. La televisión, como hemos resaltado, se ha erigido como principal espacio de aprendizaje y conocimientos culturales, desdibujando la función de la familia y la escuela. La escuela, como ente de aprendizaje y socialización, debe generar espacios en el que las interacciones y la creación verbal de narraciones para generar sentido conlleven al conocimiento de la dimensión afectiva de la persona. Con esto no se pretende negar la importancia que ha adquirido la mediación televisiva en el contexto sociocultural en que vivimos, pero sí resaltar la importancia de educar sobre los nuevos modos de leer y el papel de la escuela en estos procesos con el fin de que no se excluyan otras formas de estructuración simbólica del sujeto.

\section{Bibliografía}

Aceves Lozano, Jorge E. (1998). "La historia oral y de vida: del recurso técnico a la experiencia de investigación", en Galindo Cáceres, Luís Jesús. (Coord.). Técnicas de investigación en sociedad, cultura y comunicación. México: Prentice Hall, Pearson Education, Addison Wesley.

Barbero, Jesús Martín. (1996). La ciudad virtual: transformaciones de la sensibilidady nuevos escenarios de comunicación. Cali: Universidad del Valle.

(1987). "Televisión, melodrama y vida cotidiana” en Revista Signo y Pensamiento, no 11, 59-72. 
Barbero, Jesús Martín y Rey, Germán. (1999). Los ejercicios del ver: hegemonía audiovisual y ficción televisiva. Barcelona: Gedisa.

Bolívar, Adriana. (2002). "Epistemología de la investigación biográficonarrativa en educación" en Revista Electrónica de Investigación Educativa, no 1, pp. 1-32. (Extraído el 6 de junio de 2005 desde www. redie.uabc.mx/vol4no1/contenido-bolivar.html).

Bruner, Jerome. (2000). Actos de significado. Más allá de la revolución cognitiva. Madrid: Alianza Editorial.

(2001). Realidad mental y mundos posibles. Los actos de la imaginación que dan sentido a la experiencia. Barcelona: Gedisa.

Echeverría, Rafael. (2002). Ontología del lenguaje. Santiago de Chile: Dolmen Ediciones.

Ferrés, Joan. (1994). Televisión y educación. Barcelona: Paidós.

Fuenzalida, Valerio. (1994). "La producción de una TV. infantil de calidad" en Revista Signo y Pensamiento, no 24, pp. 93-102.

Gutiérrez, Gabriel Alba. (1998). "El mensaje narrativo. Memoria, relato, imaginario" en Revista Signo y Pensamiento, no 12, pp. 55-68.

Gallardo Paúls, Beatriz. (1998). Comentario de textos conversacionales. De la teoría al comentario. Madrid: Arco Libros.

McLuhan, Marshall y Fiore, Quentin. (1998). El medio es el masaje. Un inventario de efectos. Barcelona: Paidós.

Ochs, Elinor. (2000). "Narrativa" en Van Dijk, Teun. (Ed.). El discurso como estructura y proceso. Barcelona: Gedisa, pp. 271-303.

Pomerantz, Anita y Fehr, B. J. (2000). “Análisis de la conversación: enfoque del estudio de la acción social como prácticas de producción de sentido" en Van Dijk, Teun. (Ed.). El discurso como interacción social. Barcelona: Editorial, pp. 101-139.

Restrepo, Mariluz. (1987). "La semántica de lo cotidiano” en Revista Signo y Pensamiento, n을 11, pp. 31-44.

Rey, Germán. (1987). “Las huellas de lo social. Interacción, socialización y vida cotidiana" en Revista Signo y pensamiento, no 11, pp. 9-30.

Rincón, Omar G. (1994). "La televisión: forma y sensibilidad de nuestro tiempo" en Revista Signo y Pensamiento, no 24, pp. 57-78.

Tomlin, Russell S., Forrest, Linda, et al. (2000). "Semántica del discurso" en Van Dijk, Teun. (Ed.). El discurso como estructura y proceso. Barcelona: Gedisa, pp. 107-170.

Tusón Valls, Amparo. (1997). Análisis de la conversación. Barcelona: Ariel. 